\title{
Bancos Públicos de Desenvolvimento: uma Aproximação Teórica
}

\section{State-Owned Development Banks: a Theoretical Approach}

Victor Leonardo de Araujo*

Resumo: Diferente do que supõem as abordagens convencional e das falhas de mercado, a abordagem pós-keynesiana percebe a importância da atuação de bancos públicos, quer pelo seu papel anticíclico, quer pelo seu papel no financiamento de longo prazo para o investimento, para o desenvolvimento regional e para a inovação. Particularmente, o banco público de desenvolvimento (BPD), além de cumprir essas funções, ainda é funcional ao necessário processo de consolidação dos passivos, completando o circuito investimento-financiamento-poupança-funding nas economias baseadas no crédito. Nesta abordagem, o BPD não constitui uma solução inferior aos mecanismos de mercado, podendo, inclusive, exercer papel protagonista no financiamento do investimento. As agendas de fortalecimento dos BPD são compatíveis com esta abordagem, em lugar das agendas de fortalecimento dos mercados de capitais.

Palavras-chave: Bancos de desenvolvimento. Financiamento do investimento. Teoria pós-keynesiana.

Abstract: Unlike the conventional and the market failures' approach, the Post-Keynesian theory admits the importance of state-owned banks, because of its countercyclical role and its long-term financing role to the investment, the regional development and the innovation. Particularly, the development state-owned bank (BDP) is functional to the consolidation of liabilities' process, fulfilling the investment-finance-save-funding process in economies based on credit bank. According to this approach, BPD is not a worse solution compared to market mechanisms: it can be the protagonist actor in investment financing. Public politics to make BPD stronger are compatible with this approach, in place those that aim make capital market stronger.

Keywords: Development banks. Investment finance. Post-keynesian theory.

JEL Classification: E44, G21.

\section{Introdução}

A temática do financiamento do desenvolvimento tem engendrado uma agenda bastante profícua, especialmente em economias em desenvolvimento, nas quais as modalidades que exigem financiamento de longo prazo, como a formação bruta de capital fixo, a infraestrutura e a inovação, constituem um dos problemas estruturais. Por serem economias com mercados financeiros pouco profundos,

\footnotetext{
* Doutor em Economia pela Universidade Federal Fluminense (UFF). Professor adjunto da Faculdade de Economia da UFF. E-mail: victor_araujo@terra.com.br
} 
mercados de capitais de pequena dimensão e viés de curto prazo, o financiamento de longo prazo nessas economias é suprido por instituições financeiras de desenvolvimento, notadamente os bancos públicos de desenvolvimento (BPD).

Existe ampla literatura sobre o uso de instituições do tipo BPD. A abordagem preferencial é histórica, voltada para a análise do desempenho dessas instituições, geralmente investigando os setores beneficiados na promoção da reconstrução ou das estratégias de desenvolvimentos dos Estados a que estão submetidos. Do ponto de vista teórico, as contribuições mais numerosas são aquelas que atribuem aos BPD a função de oferecer a modalidade de financiamento de longo prazo que os bancos privados relegam a segundo plano e que os mercados de capitais não são capazes de prover. São abordagens tipicamente novo-keynesianas, nas quais os mercados financeiros são incompletos, cabendo, neste caso, a atuação dos bancos públicos. No caso particular da incompletude de mercado envolver a inexistência ou a insuficiência do mercado de capitais para mobilizar recursos de longo prazo, admite-se o uso de BPD. Por tratar-se de um tipo de intervenção estatal, esta modalidade é tratada nesta abordagem como hierarquicamente inferior aos mecanismos de mercado, ainda que seja aceitável em função das falhas de mercados que os BPD procuram suprir - e, por isso, é uma solução do tipo second best. No plano normativo, a agenda consiste não no fortalecimento dos BPD, mas em reformas capazes de desenvolver os mercados de capitais e de crédito privado, para que a economia possa, gradativamente, prescindir deste tipo de intervenção estatal.

A partir da abordagem pós-keynesiana, que rejeita a hipótese da superioridade dos mecanismos de mercado, este trabalho tem como objetivo oferecer uma aproximação teórica capaz de fundamentar arranjos nos quais os BPD não ocupem necessariamente posição hierarquicamente inferior ao mercado de capitais ou de crédito privados. Â luz dessa abordagem, mostraremos que os BPD podem constituir uma solução de mesmo nível hierárquico que os mecanismos de mercado, podendo, inclusive, ocupar papel de protagonistas no financiamento do desenvolvimento. Esta abordagem é coerente com proposições de políticas que visam ao fortalecimento dos BPD em lugar de reformas de liberalização financeira que busquem soluções privadas para o financiamento de longo prazo. $\mathrm{Na}$ abordagem proposta por este trabalho, como o aspecto relevante é a oferta estável de fontes de recursos compatíveis com a natureza dos ativos de longo prazo de maturação, discutiremos também as diversas possibilidades que envolvem a composição da estrutura dos passivos dos BPD.

O ponto de partida será discutir, na seção dois, a visão convencional e os modelos de repressão financeira que rejeitam a intervenção estatal nos mercados financeiros (e, portanto, rejeitam a atuação de BPD). A alternativa a essa visão é feita pelos modelos novos keynesianos, que discutiremos na seção três. Nesta abordagem o BPD constitui solução para o problema da incompletude dos mer- 
cados financeiros - uma solução tipo second best, de modo que o fortalecimento dos mercados privados de capitais constitui a agenda propositiva mais relevante. Na seção quatro discutiremos como a abordagem pós-keynesiana comporta a intervenção estatal via bancos públicos, chegando ao caso particular dos BPD. Mostraremos que esta abordagem é compatível com arranjos institucionais nos quais os BPD podem assumir posição no topo hierárquico e protagonizar o processo de consolidação financeira, bastando que suas fontes de recursos sejam estáveis e compatíveis com a natureza dos seus ativos, notadamente de longo prazo. Por esta razão, a seção também discute os possíveis formatos da estrutura de ativos dos BPD. Atestada a funcionalidade dos BPD para o ciclo econômico e para o processo de desenvolvimento, a agenda propositiva se desloca das reformas de liberalização financeira para a configuração mais adequada dos BPD, o que pode incluir a sua expansão, já que nesta abordagem o tamanho desta instituição não pode ser definido a priori. A seção cinco fará as considerações finais.

\section{$2 \mathrm{~A}$ Visão Convencional}

$\mathrm{Na}$ visão convencional, o debate sobre a necessidade de bancos públicos (e de desenvolvimento, em particular) remonta à discussão sobre a hipótese da eficiência dos mercados financeiros. A visão convencional, que é a forma com a qual chamaremos aquela visão baseada na formulação neoclássica, pode ser resumida nas seguintes proposições: ${ }^{1}$

(i) em mercados completos e que funcionam sob concorrência perfeita e com preços flexíveis, os agentes maximizam sua função-objetivo de modo que o resultado é a promoção de uma alocação pareto-eficiente;

(ii) o sistema de preços fornece aos agentes a sinalização de onde os recursos devem ser eficientemente alocados, na medida em que reflete o grau de escassez destes fatores: ${ }^{2}$ qualquer forma de interferência sobre o sistema de preços gera, portanto, uma alocação ineficiente;

(iii) a poupança determina o investimento: as decisões dos poupadores (ofertantes de capital) e dos investidores (demandantes de capital) são tomadas a partir de um exercício de maximização intertemporal de cada agente

$1 \quad$ Para mais detalhes sobre as proposições da teoria neoclássica, ver, por exemplo, Varian (1992).

2 Isto, por sua vez, deriva do princípio da substituição, que pode ser direta (quando a queda no preço de um fator induz à adoção de métodos de produção mais intensivos neste fator) ou indireta (quando os consumidores são induzidos a consumir uma maior quantidade de bens intensivos no fator cujo preço caiu). O princípio da substituição permite derivar uma função de demanda que depende inversamente dos preços. Por isto é que, na teoria neoclássica, o preço relativo de um bem mede o índice da sua escassez. Para maiores detalhes, ver Serrano (2001). 
econômico, no qual os poupadores transferem recursos aos investidores a uma taxa de juros que iguala oferta e demanda de capital. A taxa de juros é o custo de oportunidade; é o prêmio que o poupador recebe por abrir mão de consumo presente em troca de consumo futuro. A taxa de juros é parte integrante do sistema de preços, e como tal também é um instrumento de sinalização, e que deve ser o suficientemente flexível para garantir o equilíbrio entre poupança e investimento.

(iv) as instituições financeiras têm um papel neutro, ou passivo: apenas transferem as poupanças dos poupadores para os investidores.

Dentro da visão convencional, o modelo proposto por Gurley e Shaw (1955) é o pioneiro a abordar a relação entre o papel dos intermediários financeiros e o desenvolvimento econômico. O modelo pressupõe que o sistema econômico seja composto por unidades superavitárias e unidades deficitárias. Estas últimas podem ser deficitárias seja porque consomem mais do que a renda corrente, ou porque investem mais do que poupam. A transferência direta da poupança das unidades superavitárias para as unidades deficitárias incorre em custos elevados, seja pela análise que as unidades superavitárias têm de fazer do retorno e dos riscos dos empréstimos, seja pela dificuldade em encontrar agentes deficitários dispostos a aceitar as condições do empréstimo que as unidades superavitárias desejam fazer. A intermediação financeira tende a reduzir esses custos. Do ponto de vista macroeconômico, a intermediação financeira eleva a poupança agregada, pois incentiva a poupança individual dos agentes. Assim, do ponto de vista macro, o modelo relaciona o desenvolvimento dos mercados financeiros com o desenvolvimento econômico. Do ponto de vista micro, o modelo Gurley-Shaw generaliza para os mercados financeiros os resultados segundo os quais o livre mercado promove a alocação mais eficiente dos recursos. ${ }^{3}$

A hipótese da eficiência dos mercados financeiros remete a outra, comumente associada à visão convencional: a hipótese da repressão financeira, apresentada de forma pioneira por Shaw (1973) e McKinnon (1973), e que pode ser sintetizada da forma a seguir. Em economias em que a taxa de juros real é artificialmente baixa (em decorrência da intervenção estatal) os mercados financeiros não se desenvolvem. Os agentes não têm estímulo a poupar, o que traz um duplo resultado. Em primeiro lugar, os investimentos - determinados pela disponibilidade de poupança - são baixos e a economia tende a registrar baixas taxas de crescimento. Em segundo lugar, o governo é obrigado a financiar-se via emissão monetária, o que resulta em inflação e em redução da taxa real de juros, reforçando o processo. De acordo com a hipótese de repressão financeira, taxas de juros inferiores à de equilíbrio (market-clearing interest rates) levam a outras distorções, entre as quais a maior alo-

3 Para uma maior defesa da liberalização financeira, ver Fry (1997). 
cação de recursos em projetos capital-intensivos, ou em projetos menos lucrativos. Para evitar tais distorções, a solução sugerida é o aumento das taxas de juros reais, interrompendo a política de concessão de crédito "barato" a um número reduzido de tomadores privilegiados (MCKINNON, 1973, p. 79).

$\mathrm{Na}$ visão convencional, cabe ao mercado financeiro um papel meramente passivo, qual seja, o de transferir recursos dos poupadores para os "despoupadores" (consumidores ou investidores). Não faz parte da agenda da visão convencional qualquer discussão sobre a configuração do sistema financeiro, exceto no que diz respeito à sua liberalização. Ou, como resume Studart (1994, p. 373), sobre a visão convencional: "mercados de capitais perfeitamente competitivos suprirão as economias com todas as suas necessidades de financiamento, sejam elas de curto ou longo prazo". ${ }^{4}$

Assim, nesta abordagem, qualquer proposta de segmentação do mercado financeiro é combatida, porque significa taxas de juros diferenciadas e, portanto, alocação ineficiente de recursos.

Se a distinção entre financiamento de curto e longo prazo não é relevante na abordagem convencional, a criação de instituições especializadas merece o mesmo tratamento. Fry (1997, p. 313-314), ao discutir a eficiência dos mercados de capitais na presença de instituições financeiras de desenvolvimento (IFD's) - entre as quais os bancos públicos de desenvolvimento -, aponta as experiências como "desapontadoras". Para ele, a existência de bancos de desenvolvimento tende a agravar o quadro de repressão financeira, uma vez que esse tipo de instituição tradicionalmente opera com taxas de juros menores. Fry aponta ainda outros problemas com instituições deste tipo: (i) juros baixos as tornam instituições incapazes de serem autossuficientes e mobilizar recursos em termos comerciais; (ii) dívidas em atraso, em especial em períodos de recessão econômica, agravam a incapacidade de autofinanciamento dessas instituições; (iii) não consideram risco e retorno dos projetos que financiam, atuando meramente como instrumento de projetos desenvolvimentistas governamentais; e (iv) segmentam o mercado de capitais, gerando uma falha de mercado que levaria a uma distorção: parte do mercado de capitais funcionaria sob racionamento de crédito a taxas de juros reais baixas ou até mesmo negativas, enquanto outra parte funcionaria sob taxas de juros mais elevadas.

Além de vários desses, Ferreira, Freitas e Schwartz (1998, p. 76) ainda enunciam mais um dos argumentos usados pela teoria convencional para rejeitar o uso de bancos de desenvolvimento: tais instituições atuam em mercados de tomadores de alto risco, e financiam projetos "[...] cujos retornos esperados são relativamente baixos, inferiores ao aceitável em termos comerciais”.

$4 \quad$ Do original: "perfectly competitive capital market will supply the economy with all its needs of financing, be it short or long term." 
Nesse sentido, existe uma grande variedade de trabalhos publicados pelo Banco Mundial apontando uma suposta ineficiência na alocação de recursos, de um modo geral a partir da intervenção governamental no mercado financeiro, e de um modo particular a partir dos bancos públicos de desenvolvimento. Para Vittas e Cho (1995, p. 5), a interferência do governo na alocação de crédito leva à corrupção, rent-seeking e crowding out, sendo raros os casos de intervenção governamental bem-sucedida, como seriam os casos do Japão e da Coreia, "[...] mas para a ampla maioria dos países em desenvolvimento, políticas de crédito levaram a severas distorções no mercado e falharam em promover crescimento e desenvolvimento". 5

Para Cho e Sheng (2002), a prática de muitos bancos de desenvolvimento em ter uma alta concentração de empréstimos de alto risco a taxas fixas sem uma base estável de funding de longo prazo teria levado muitos deles à falência.

Para Kane (1977 apud YEYATI; MICCO; PANIZZA, 2004, p. 58), a intervenção estatal distorce a alocação de crédito, que passa a ser determinada por razões políticas em lugar das razões econômicas. Além disso, o crédito seletivo teria custos associados, como o uso ineficiente de recursos produtivos. Como os custos são implícitos, a dificuldade de mensurá-los leva a acreditar que tais políticas são mais baratas do que efetivamente são.

\section{A Abordagem das Falhas de Mercado}

Embora a abordagem que assume a existência de falhas de mercado seja subproduto da velha teoria neoclássica, ela admite (ao contrário dos suas antecessoras) a intervenção estatal no mercado financeiro, ainda que dentro das limitações impostas pelo preenchimento das lacunas deixadas pelo setor privado - que resultam das tais falhas.

Stiglitz e Weiss (1981) apontam a assimetria de informações como uma das principais falhas de mercado, e que tem efeitos particulares no mercado financeiro. A existência de assimetria de informação se caracteriza por cada participante do mercado desconhecer todas as informações sobre o outro: o tomador de empréstimos tem informações melhores do que o emprestador sobre o risco e o retorno potencial do projeto para o qual está solicitando o empréstimo. ${ }^{7} \mathrm{O}$ resultado é o racionamento de crédito: os emprestadores se recusam a emprestar mesmo que o tomador esteja disposto a pagar juros mais altos. O excesso de demanda por crédi-

$5 \quad$ "But in the vast majority of developing countries, credit policies have given rise to severe market distortions and have failed to promote growth and development."

6

KANE, E. Good intention or unintended evil: the case against selective credit allocation. ， v.9, n. $1,1977$.

7 Um bom resumo do problema da assimetria de informações pode ser encontrado em Carvalho et al. (2000: p. 79-82). 
to não se traduz em aumento das taxas de juros - ou seja, os preços não aumentam para eliminar o excesso de demanda.

Nesse mercado, a assimetria de informações conduziria aos problemas de seleção adversa e risco moral. Se o excesso de demanda por crédito fosse eliminado via aumento das taxas de juros - como supõe a teoria convencional - automaticamente seriam eliminados do mercado aqueles tomadores de empréstimo cujos projetos são menos arriscados, permanecendo somente os projetos mais arriscados. Para evitar isso, o emprestador evita elevar as taxas de juros e raciona crédito. Esse problema ficou conhecido como seleção adversa, e ocorre antes da transação se efetuar. O segundo problema, também associado à existência de assimetria de informações, é o risco moral (moral hazard), que é o risco de o tomador de empréstimos utilizar os recursos emprestados em um projeto distinto daquele para o qual o emprestador concedeu o financiamento. Se isto ocorrer, e o referido projeto malograr, o tomador provavelmente não conseguirá honrar os seus compromissos. Por isso, o emprestador prefere conceder empréstimos de menor montante a taxas de juros mais baixas, e raciona o crédito.

Stiglitz (1993) combate ainda a hipótese da repressão financeira: num ambiente de informação imperfeita, o processo de alocação deixa de ser baseado nos preços. ${ }^{8}$ Ademais, segundo Stiglitz, não haveria evidências quanto à relação entre taxa de juros e poupança.

Um tipo específico de falha de mercados que pode ser observada nos países em desenvolvimento constitui aquilo que se convencionou chamar de incompletude dos mercados. Segundo Stiglitz (1993), em economias menos desenvolvidas os mercados financeiros são incompletos: os mercados de capitais são fracos e os mercados acionários, muitas vezes, inexistem. Os bancos, por sua vez, tendem a privilegiar os empréstimos de curto prazo. Haveria, por parte do setor privado, um desinteresse em financiar projetos que, embora tenham um alto retorno social, têm um baixo retorno privado e alto risco.

Geralmente, as falhas de mercado em criar instituições apropriadas podem ser devido à falta de empresários no setor privado, à falta de criatividade ou à falta de vontade de assumir riscos; ou ao fato de que os retornos privados esperados pela instituição são geralmente menores que os retornos sociais. (STIGLITZ, 1993, p. 28) ${ }^{9}$

A existência de falhas de mercado e, portanto, o não alcance dos resultados esperados pela teoria convencional, justificaria formas de intervenção governa-

8 "Because of information imperfections, banks are involved, in any case, in a non-price allocation process." (STIGLITZ, 1993, p. 28).

9 "Often, the markets failure to create appropriate institutions may be due to a lack of entrepreneurship in the private sector, a lack of creativity or an unwillingness to bear risks; or to the fact that the expected private returns to the institution often are markedly less than social returns." 
mental. ${ }^{10}$ Para Stiglitz (1993 ${ }^{11}$ apud FRY, 1997, p. 759). "[...] existem formas de intervenção do governo que não somente farão o mercado funcionar melhor como também melhorarão a performance da economia". ${ }^{12}$ Em mercados financeiros, segundo Stiglitz (1993), as falhas de mercado tendem a ser mais difusas do que nos outros mercados, o que justificaria a intervenção governamental. As formas sugeridas de intervenção seriam: (i) criação de instituições de mercado; (ii) regulação de tais instituições; (iii) intervenção em tais instituições através de mecanismos regulatórios; (iv) intervenção direta nos mercados de capitais; e (v) outras formas de intervenção. Stiglitz (1993) cita o uso dos bancos de desenvolvimento pelos países hoje desenvolvidos como uma forma exitosa de solucionar os problemas apontados até aqui.

A incompletude dos mercados financeiros é, ao lado da assimetria de informações, outro fator impeditivo ao seu funcionamento eficiente. Na ausência de agentes dispostos a conceder financiamento de longo prazo, os demandantes deste tipo de empréstimo seriam obrigados a recorrer a sucessivos financiamentos de curto prazo, correndo o risco inerente às oscilações das taxas de juros.

Ao contrário do que a alguns possa parecer, o livre mercado tem dificuldades para abordar algumas peculiaridades dos investimentos produtivos, uma vez que a sua maturação prolongada e a incerteza quanto aos resultados de longo prazo implicam, quase sempre, altos riscos, os quais o capital financeiro privado, orientado, basicamente, para objetivos microeconômicos, procura evitar. (YOSHINO, 1994, p. 37)

A despeito dessa tradição teórica admitir a intervenção estatal nos mercados financeiros, essa deve ficar circunscrita ao suprimento das falhas de mercado - isto

10 Nem todos os economistas que utilizam a abordagem de falhas de mercado tipicamente oriundas da assimetria informacional concordam que a intervenção governamental vá gerar necessariamente resultados superiores. Para alguns, as falhas de governo podem ser piores do que as falhas de mercado. Vittas e Cho (1995) defendem que, se houver necessidade de promover algum tipo de intervenção governamental, é melhor fazê-lo por meio de políticas de direcionamento de crédito do que através das formas convencionais, como a proteção tarifária. Embora admitam que o direcionamento de crédito pode ser uma solução para os problemas decorrentes da assimetria de informações, os autores também acreditam que "[...] governos nem sempre fazem a coisa certa”. O envolvimento do Governo na alocação de crédito pode resultar, e geralmente resulta, em rent-seeking por parte dos tomadores de empréstimo, corrupção por parte dos banqueiros e funcionários públicos, e crowding-out dos projetos igualmente desejáveis (VITTAS; CHO, 1995, p. 280). É evidente que o debate entre falhas de mercado e falhas de governo é imbuído de um forte grau de subjetividade e ideologia. De acordo com Carvalho (2001, p. 392), não existe nenhuma garantia que as falhas de governo sejam maiores do que as falhas de mercado.

11 STIGLITZ, J. The role of the state in financial markets. The World Bank Economic Review, v. 7, n. 1, p. 19-52, 1993.

12 Do original: "there exist forms of government intervention that will not only make these markets function better but will also improve the performance of the economy." 
é, os bancos públicos em geral e os de desenvolvimento em particular devem atuar apenas nos segmentos nos quais o setor privado deixa lacunas.

Para Titelman (2003), em países como os latino-americanos, nos quais os mercados financeiros são de menor tamanho, menos sofisticados e com história inflacionária, haveria concentração de financiamento nas modalidades de curto prazo, e os bancos públicos de desenvolvimento poderiam desempenhar um papel de fomento ao setor produtivo, "seja facilitando o acesso ao financiamento a agentes excluídos deste processo e/ou como catalisador e impulsor de novas modalidades de intermediação financeira" (TITELMAN, 2003, p. 15).

Yoshino (1994) também justifica a intervenção governamental via instituições financeiras especializadas no desenvolvimento, tais como bancos de desenvolvimento, no mercado de crédito a partir do desinteresse do setor privado em financiar determinados setores. Para Ferreira, Freitas e Schwartz (1998, p. 75), nos países em desenvolvimento

o setor privado não desenvolveu instituições adequadas ao financiamento de longo prazo com o propósito de investimento, relegando essa tarefa ao setor público. O papel central do governo na promoção do desenvolvimento levou à formação de instituições com a atribuição específica de identificar, promover, financiar e implementar projetos de investimento.

Yeyati, Micco e Panizza (2004) resumem como sendo quatro os argumentos que justificam a intervenção governamental no mercado financeiro: (i) garantir a segurança e a solvência do sistema bancário; (ii) mitigar as falhas de mercado decorrentes dos custos da obtenção da informação, bem como da assimetria de informações; (iii) financiar projetos que, embora sejam socialmente desejáveis, são de baixa lucratividade (e que, por essa razão, não despertam o interesse do setor financeiro privado); e (iv) promover o desenvolvimento financeiro e garantir o acesso a serviços bancários competitivos aos que residem em áreas isoladas. A intervenção governamental no mercado de crédito, particularmente através de bancos estatais, garantiria financiamento a setores que o setor privado, tipicamente, não se sente estimulado a financiar, como a agricultura, os setores intensivos em PEBD ou em capital. Ademais, "[...] em um contexto de pobre desenvolvimento institucional e desconfiança geral dos bancos privados, os bancos estatais seriam as únicas instituições financeiras viáveis" (YEYATI; MICCO; PANIZZA, 2004, p. 12). ${ }^{13}$ Os bancos estatais ainda podem contribuir para suavizar o ciclo econômico, expandindo o crédito em períodos recessivos.

A abordagem das falhas de mercado tem inspirado não somente os principais argumentos favoráveis à intervenção estatal no mercado financeiro, como

13 "[...] in a context of poor institutional development and a general mistrust of private banks, stateowned banks could be only viable financial institutions". 
também inspirou as definições para bancos de desenvolvimento. A definição original utilizada por Diamond (1957) e Boskey (1959), segundo a qual o banco de desenvolvimento é uma instituição destinada a conceder empréstimos de longo prazo (p. 2), foi lapidada por outros autores, como Aghion (1999) e Yeyati, Micco e Panizza (2004), que trataram de incorporar o fato dessas instituições financiarem projetos em modalidades tradicionalmente relegadas a segundo plano pelos bancos privados. Segundo Yeyati, Micco e Panizza (2004, p. 16), bancos de desenvolvimento seriam instituições provedoras de capital de longo prazo para projetos imbuídos de externalidades, mas que, contudo, não encontram financiadores privados, como, por exemplo, financiamento agrícola e projetos de redução de desigualdades regionais, que são modalidades tipicamente atingidas pelo racionamento de crédito - típicas falhas de mercado. Todas essas definições têm um ponto em comum: assumem que o papel do banco de desenvolvimento é atuar em algum segmento que, embora relevante para o desempenho econômico, é relegado a segundo plano pelos mecanismos de mercado.

Fica claro nas abordagens que assumem a existência de falhas de mercado que os bancos de desenvolvimento são uma solução do tipo second best. Ou seja, se os mercados financeiros não possuíssem tais falhas - ou seja, se os mercados financeiros fossem completos e não existisse assimetria de informação -, os resultados obtidos seriam aqueles previstos pela teoria convencional: alocação ótima de recursos, que nos mercados financeiros em particular corresponderia a uma situação na qual o financiamento do investimento seria provido de forma a assegurar uma trajetória compatível com o crescimento de longo prazo em condições equilibradas. Na existência de falhas, contudo, admite-se a intervenção estatal em particular, admite-se o uso de bancos de desenvolvimento de caráter público (doravante bancos públicos de desenvolvimento, ou BPD) para suprir falhas específicas do mercado financeiro, como as modalidades de longo prazo e/ou o financiamento de setores geradores de externalidades positivas do ponto de vista social, ainda que pouco lucrativas.

Do ponto de vista normativo, essa abordagem não só delimita a atuação do BPD ao suprimento das falhas de mercado, como também estabelece uma agenda de reformas que busquem "completar" o mercado financeiro - desenvolvimento do mercado financeiro, particularmente nas modalidades de prazo mais longo. Em geral, essas reformas ainda são combinadas com outras políticas que visem assegurar maior lucratividade para as atividades geradoras de externalidades positivas do ponto de vista social, como as parcerias público-privadas. Como pano de fundo, a supremacia do mecanismo de mercado contrapõe-se à intervenção estatal, inerentemente falha, o que justificaria uma agenda de restrições cada vez mais limitadoras da atuação estatal. Assim, por exemplo, reformas financeiras visando "completar" os mercados financeiros - particularmente as modalidades de longo 
prazo, por meio do aprofundamento dos mercados privados de capitais - seriam preferíveis a políticas de expansão da atuação dos BPD.

As próximas seções discutirão, a partir da abordagem pós-keynesiana, a possibilidade da solução representada pelos BPD ser do tipo first best: em vez de um mal necessário, seria uma instituição desejada e recomendada.

\section{A Abordagem Pós-Keynesiana: dos Bancos Públicos aos Bancos Públicos de Desenvolvimento}

Como parte da aproximação teórica a que nos propusemos, ofereceremos primeiro uma abordagem teórica para tratar bancos públicos em geral, para, em seguida, tratar do caso específico dos bancos de desenvolvimento.

\subsection{Bancos Públicos segundo a Abordagem Pós-Keynesiana}

O ponto de partida da abordagem pós-keynesiana é o princípio da demanda efetiva (PDE) como explicativo da dinâmica macroeconômica. Segundo o PDE, os níveis de emprego e de renda da economia dependem dos gastos autônomos em investimento. O consumo induzido amplia esse impulso autônomo por meio do multiplicador. Um dos resultados mais notáveis do PDE é a inversão da Lei de Say, que supõe a causalidade da poupança para o investimento, advogando exatamente o oposto: a expansão da renda que resulta ao término do processo gerará também uma expansão da poupança que a iguala, ex-post, ao investimento inicial. O investimento, segundo os keynesianos, depende das decisões dos empresários, tendo por base o retorno esperado dos ativos de capital, e não depende de poupança prévia: em um sistema de moeda fiduciária no qual os bancos têm a prerrogativa de criar moeda escritural, o financiamento do investimento depende da disposição dos bancos em disponibilizar os recursos iniciais de que o empresário necessita. A operação é meramente contábil e tem como restrição inicial a capacidade e a disposição dos bancos em se alavancar, o que, em última instância, será determinado pelo estado de confiança da economia (KEYNES, 1964).

É preciso, pois, compreender quais são os determinantes do comportamento da firma bancária. Autores de tradição pós-keynesiana construíram uma teoria da firma bancária a partir dos conceitos de preferência pela liquidez e incerteza, por analogia ao comportamento dos demais agentes econômicos.

Segundo Carvalho (2007), a teoria da preferência pela liquidez formulada por Keynes é comumente entendida como uma teoria da demanda por moeda a partir dos motivos transação, precaução, especulação e finance. Entretanto, mais do que uma teoria da demanda por moeda, essa abordagem constitui, na verdade, uma 
teoria de escolha de ativos na qual os agentes econômicos levam em consideração os retornos esperados das diferentes classes de ativos vis-à-vis o atributo de liquidez de cada uma delas. O retorno monetário de um ativo é composto por três componentes: a taxa de quase-renda (q), o custo de carregamento associado à sua manutenção (c), e seu valor de mercado (a). O investidor estará disposto a abrir mão da soma desses componentes $(\mathrm{q}+\mathrm{c}+\mathrm{a})$ em troca de um ativo que ofereça conveniência e segurança ao seu possuidor sempre que preferir manter um portfólio flexível o suficiente para recompor suas estratégias sob diferentes cenários - atributos associados à sua liquidez. Assim, a preferência pela liquidez é medida em termos do trade-off entre $(\mathrm{q}+\mathrm{c}+\mathrm{a})$ e o prêmio pela liquidez. Os agentes optam por incorporar aos seus portfólios ativos menos rentáveis, porém mais líquidos, porque a liquidez é o atributo que fornece conveniência e segurança potencial ao possuidor do ativo: quanto mais líquidos, maior será a flexibilidade que esses ativos oferecem, porque permitem ao seu possuidor recompor suas estratégias sob diferentes cenários (PAULA, 1999). Agentes econômicos preferem liquidez em resposta aos cenários de maior incerteza, em que essa flexibilidade constitui a estratégia mais adequada na gestão de seus ativos. Essa incerteza, por sua vez, é do tipo não-probabilística, e está associada ao caráter conjectural do futuro, cujo total desconhecimento explica a natureza especulativa das decisões de produção e de investimento, que são formuladas a partir de expectativas formuladas pelos empresários, que podem ou não se confirmar (FEIJÓ, 1999).

Os bancos, como quaisquer outros agentes econômicos, também possuem preferência pela liquidez e, como tal, também constituem seus portfólios "de modo a conciliar lucratividade e escala de preferência pela liquidez" (PAULA, 1999, p. 173). A atividade bancária possui uma especificidade: o sistema financeiro produz e negocia direitos sobre renda futura, cujas estimativas envolvem risco, incerteza e graus variados de confiança nos cenários formulados (HERMANN, 2011). Sob maior incerteza, os bancos, à maneira dos agentes econômicos em geral, também recompõem suas carteiras de ativos incorporando os de maior grau de liquidez, em detrimento daqueles que oferecem menor liquidez a despeito da maior rentabilidade. Com efeito, reduzem as operações de crédito, cujo grau de liquidez é inferior a algumas classes de ativos financeiros. Ao contrário, sob expectativas otimistas, os bancos tendem a privilegiar rentabilidade sobre liquidez, elevando a participação das operações de maior risco em seus ativos (PAULA, 1999), o que inclui as operações de crédito. Diz-se, por esta razão, que o comportamento dos bancos é pró-cíclico. Mais ainda: este comportamento tende a amplificar as fases do ciclo econômico. Especialmente nas fases de desaceleração econômica, quando as expectativas se tornam pessimistas, os bancos reduzem as operações de crédito, prolongando as recessões (PAULA, 2014). 
Sob esta perspectiva, é possível afirmar que o arcabouço keynesiano contempla um espaço importante para atuação de bancos públicos: a ação anticíclica, expandindo as operações de crédito nos momentos de reversão do estado de confiança da economia e contra-arrestando, total ou parcialmente, a contração do crédito por parte dos bancos privados resultante da deterioração das expectativas. Essa ação deve ser parte integrante do conjunto de políticas historicamente identificadas com o keynesianismo e adotadas com o intuito de promover a ação estabilizadora na economia, complementando a política fiscal conduzida no sentido de ampliar o gasto público, e sendo parte integrante da política monetária. Por não terem como objetivo final a maximização do lucro, os bancos públicos possuem espaço para atuarem fora da lógica imposta pelo trade-off entre $(\mathrm{q}+\mathrm{c}+\mathrm{a})$ e o prêmio pela liquidez, ainda que não de forma limitada. ${ }^{14}$

Em razão do comportamento exposto até aqui, Minsky (2009, p. 314) afirmou que "bancos e banqueiros não são administradores passivos do dinheiro a ser emprestado ou investido" como supõe a teoria convencional: as suas decisões de recompor seus ativos com maior/menor participação daqueles de maior rentabilidade, elevando/reduzindo a oferta de crédito, significam que os bancos fazem uma gestão ativa dos seus balanços. Quando o público escolhe as modalidades de depósitos também influenciados pela comparação entre risco e retorno das aplicações, preferindo maior liquidez sob cenários de maior incerteza, os bancos devem adequar suas operações ativas ao perfil de suas obrigações. O oposto também é verdadeiro: os bancos também fazem uma gestão dos seus passivos buscando adequar a natureza das obrigações por ele emitidas aos prazos e riscos dos seus ativos. Por exemplo, ao incorporar em sua carteira de ativos as operações de crédito de prazo mais longo, o banco deve certificar-se de que tais operações não devem ter como contrapartida operações passivas de prazo mais curto, como depósitos à vista. Em outras palavras, o banco deve gerir o seu balanço "com base na escolha entre quanto e quais tipos de ativos comprar e quanto e quais tipos de obrigações emitir" (OLIVEIRA, 2007, p. 181). Essa gestão, contudo, não requer a perfeita coincidência entre as maturidades do ativo e do passivo, porque a natureza da atividade bancária admite - ou mesmo requer - que se aceite algum descasamento entre elas: sob maior aversão ao risco, o banco diminui este descasamento, ainda que ao custo de menores taxas de lucro (PAULA, 2000). É neste sentido que Carvalho (2007, p. 15) afirma que é possível "ler" a preferência pela liquidez de cada banco em seu balanço: ela exerce influência sobre a escolha das classes de ativos

14 A ação anticíclica pode reduzir as margens de lucro do banco público, já que seu objetivo primeiro não seria a maximização do lucro, mas sim, neste caso, a capacidade de contra-arrestar os efeitos recessivos que o padrão de atuação do setor bancário privado impõe. As limitações são dadas pela própria margem de lucro, já que, se incorrer em prejuízos sistemáticos, o banco terá de ser socorrido pelo tesouro, se a operação incluir aportes de capital, ou pelo banco central, se houver risco sistêmico. 
que os bancos irão incorporar, assim como sobre o tipo e o prazo de obrigações que deverão emitir.

Mas, ainda que o descasamento entre as maturidades seja algo inerente à atividade bancária, há limites para que isto ocorra, em razão do risco da atividade. Segundo Paula (2000), esses riscos são de três tipos. O primeiro é o risco de crédito, associado à possibilidade de não pagamento das obrigações por parte do devedor, a qual, por sua vez, está associada ao sucesso do empreendimento que originou a operação de financiamento. A geração de um fluxo de receitas compatível com o pagamento dos juros e das amortizações depende do bom desempenho da economia. O segundo tipo é o risco de taxa de juros, já que as taxas que remuneram tanto as operações passivas como as ativas podem variar, impactando o balanço líquido dos rendimentos com juros da instituição bancária. Finalmente, o terceiro é o risco de liquidez, resultado das diferenças de maturidade entre as operações ativas e passivas: quanto maior for este descasamento, maiores serão as dificuldades de o banco atender a uma maior demanda por liquidez dos seus clientes, o que pode afetar a confiança do público quanto à sua capacidade em honrar suas obrigações. Ainda que a insuficiência temporária de liquidez possa ser suprida no mercado interbancário, essas operações envolvem um custo para o banco.

Deste modo, a existência, no balanço do banco, de operações de crédito mais longas lastreadas em passivos de maturidade inferior, embora usual, tem limites impostos pelo risco inerente à atividade bancária. Por este motivo, bancos comerciais, ou bancos múltiplos em que prepondere a carteira comercial, oferecem operações de crédito com prazos mais curtos. Ou, de modo mais geral, economias em que o setor bancário não consegue alongar os prazos de suas operações passivas têm maiores dificuldades em prover financiamento de longo prazo por meio desses tipos de instituição. A formação bruta de capital fixo e a construção de moradias, atividades de longo prazo de maturação, requerem modalidades de financiamento de longo prazo, sob pena da economia se expor ao risco de taxa de juros, caso as operações tenham que ser sucessivamente roladas em modalidades vincendas no curto (ou mesmo no médio) prazo.

Em geral, os projetos que envolvem prazos mais longos têm menor liquidez e são imbuídos de uma componente maior de incerteza, especialmente quando se tratam de projetos voltados à introdução de novos setores antes inexistentes na estrutura produtiva. Estão incluídos aqui os investimentos em infraestrutura e inovação. Os primeiros envolvem custos elevados em construção civil, que geralmente possuem um componente de imprevisibilidade ${ }^{15}$ que amplia o grau de incerteza comparativamente a outras modalidades de operações. Os elevados prazos de maturação associados à incerteza inerente a esses projetos também tendem

15 Ver, a este respeito, Carneiro (2002). 
a afastar os financiadores privados desse mercado, que podem preferir incorporar em suas carteiras de ativos investimentos menos ilíquidos e de retorno menos incerto, notadamente os de curto e médio prazo. Ou, em termos pós-keynesianos, os bancos tendem a administrar suas operações ativas de modo a rejeitar parte dessas operações. As maiores empresas, já consolidadas em seus respectivos mercados, teriam maior facilidade em obter financiamento mesmo nas operações de prazos mais longos, porque os bancos tendem a associar essas empresas e seus empreendimentos a um menor grau de risco e acomodar a operação de financiamento mesmo em um cenário de maior incerteza. Nesse caso, os bancos teriam apenas de conciliar a propensão a incorporar ativos realizáveis a longo prazo com sua estrutura de passivos. De todo modo, o resultado deste processo tende a favorecer a consolidação de uma estrutura produtiva pré-existente, compatível com as empresas já consolidadas que atuam em seus respectivos setores. Ocorre, pois, que o processo de desenvolvimento econômico, entendido como diversificação da estrutura produtiva, requer a incorporação de novos ramos de atividade, notadamente aquelas de maior produtividade, em geral intensivas em capital e com maior prazo de maturação, muitas vezes empreendidas por novos entrantes no mercado. Ou seja, o processo de desenvolvimento requer financiamento de longo prazo, em setores associados a graus de incerteza mais elevados.

O mesmo ocorre quanto à inovação. Trata-se de uma modalidade de investimento também imbuída de enorme incerteza e elevado tempo de maturação. Essa modalidade requer elevada capacidade de concentração de capital, porque os seus custos são elevados, em geral associados ao pagamento de salários de profissionais altamente qualificados (LUNA; MOREIRA; GONÇALVES, 2008) e equipamentos.

Sob este aspecto, a abordagem pós-keynesiana abre outro campo de atuação para os bancos públicos: o financiamento de longo prazo para a formação bruta de capital, seja para sustentar as taxas de crescimento do produto, seja para sustentar projetos de desenvolvimento econômico com transformação da estrutura produtiva e com atividades inovadoras. Se o financiamento de longo prazo constituir um dos papeis destinados à instituição, o banco deve ser formatado de modo que suas operações passivas sejam longas, já que se espera desse tipo de instituição uma maior participação de operações ativas de longo prazo.

Finalmente, a aplicação dos conceitos de incerteza e preferência pela liqui$\mathrm{dez}$, quando combinados às categorias de centro e periferia, ${ }^{16} \mathrm{em}$ abordagem

16 Ver Bielschowsky (2000), Busato (2012). 
originalmente formulada por Dow $\left(1982,{ }^{17} 1987,{ }^{18} 1990^{19}\right.$ apud AMADO, 1997),${ }^{20}$ permite outro campo de atuação para os bancos públicos: o desenvolvimento regional. Segundo Amado (1997), a periferia se caracterizaria por uma dinâmica econômica instável, com alta propensão a importar, estrutura produtiva pouco diversificada e concentrada nos setores primário e terciário, e sua dinâmica macroeconômica é dada exogenamente. Além disso, na periferia o grau de desenvolvimento dos mercados financeiros é baixo e os ativos são menos líquidos. Dessa forma, o grau de incerteza na periferia tende a ser superior ao centro, e a preferência pela liquidez também tende a ser mais elevada - incluindo a preferência pela liquidez das instituições financeiras que operam na periferia (NOGUEIRA; CROCCO; SANTOS, 2010). Ou seja, os bancos tendem a ofertar relativamente volumes menores de crédito para a periferia, deslocando recursos para o centro e gerando um círculo vicioso: as condições periféricas determinam o baixo volume de crédito, o que agrava as condições iniciais. "Não há mecanismos endógenos capazes de romper essa dinâmica concentradora. Portanto, a única forma de revertê-la é a introdução de elementos exógenos" (AMADO, 2010, p. 221). O Estado pode constituir esse elemento exógeno por meio dos bancos públicos.

Dessa forma, a intervenção estatal por meio de bancos públicos constitui a solução para tornar viável o financiamento de tais operações. Deste modo, as seguintes funções podem ser atribuídas a bancos públicos, todas compatíveis com a abordagem pós-keynesiana: (i) ação anticíclica; (ii) financiamento da formação bruta de capital fixo; (iii) financiamento do desenvolvimento regional; e (iv) financiamento da inovação.

Segundo essa abordagem, a função do banco público não consiste em preencher lacunas decorrentes de falhas de mercado. A abordagem pós-keynesiana prescinde da hipótese da informação imperfeita ou assimétrica, bem como da hipótese da incompletude dos mercados. Ainda que a informação fosse perfeita, simétrica e os mercados fossem completos, os atributos de rentabilidade e liquidez de cada ativo associados à incerteza da atividade que pretende ser financiada (inovadora, intensiva em capital, de longo prazo de maturação) já seriam suficientes para provocar insuficiência de oferta de crédito. Esses atributos seriam mais intensos nas economias periféricas, especialmente para o financiamento das atividades tipicamente associadas ao processo de desenvolvimento econômico. São as características intrínsecas a essas modalidades - e não as falhas de mercado - que in-

17 DOWN, S. C. The regional composition of the Money multiplier process. Scottish Journal of Political Economy, v. 19, n. 1. 1982.

18 DOWN, S. C. The treatment of money in regional economics. Journal of Regional Science, v. 27, n. 1. 1987.

19 DOWN, S. C. Financial markets and regional development: the Canadian experience. Aldershot: Abebury, 1990.

20 Recomenda-se também consultar Crocco, Figueiredo e Santos (2010). 
tensificam o grau de incerteza a elas associadas, e que levam as instituições financeiras privadas a optarem pela liquidez, rejeitando incorporá-las em suas carteiras.

Por essa razão, não se pode afirmar que a solução oferecida pelos bancos públicos seja do tipo second best, como sugerem as teorias das falhas de mercado. ${ }^{21}$ Em razão do já descrito comportamento intrínseco à atividade bancária privada, os bancos públicos constituem um tipo de solução que não necessariamente será hierarquicamente inferior à solução oferecida pelos mecanismos de mercado. A atuação dos bancos públicos não deve se restringir a apenas complementar a atuação privada, podendo inclusive disputar o protagonismo no financiamento das atividades produtivas, atuando de forma funcional ao processo de sustentação do crescimento do produto, da transformação da estrutura produtiva e do financiamento do investimento e da inovação.

\subsection{Bancos Públicos de Desenvolvimento (BPD)}

O setor bancário possui outra função crucial nas economias monetárias de produção: suprir as empresas com a liquidez necessária para seus planos de produção e para as fases iniciais do plano de investimento (ZONINSEIN, 1989).

Segundo o PDE, o investimento determina o nível de renda, e não requer poupança prévia para disponibilizar os recursos necessários ao seu financiamento. A inexistência de restrição de poupança para o processo de expansão econômica não significa, contudo, que não exista qualquer impedimento ao processo de expansão econômica. De acordo com a tradição pós-keynesiana, os empresários que desejam investir devem ter acesso ao crédito bancário para a mobilização dos recursos iniciais. Como já vimos na subseção 3.1, tais recursos não são obtidos através de quantias previamente poupadas, porque os bancos comerciais têm a prerrogativa de criar moeda por mero instrumento contábil - o processo de criação de moeda escritural nas economias modernas cujos sistemas bancários funcionam sob a forma de reservas fracionárias. Esses fundos rotativos que permitem ao empresário dar início ao processo de investimento constituem o motivo finance para demanda por moeda. Também já discutimos na subseção anterior o comportamento da firma bancária e os determinantes que a levam a expandir a oferta de crédito, particularmente aqueles associados ao investimento.

Como o investimento envolve, por definição, projetos de prazo de maturação mais longos, a empresa investidora, ao mesmo tempo em que conseguiu mobilizar os recursos preliminares para seu plano de investimentos, também deve

21 Segundo as abordagens das falhas de mercado, caso não houvesse as tais falhas, as instituições financeiras privadas se encarregariam de financiar tais atividades, e o resultado seria aquele previsto pela teoria convencional. A existência das falhas, contudo, abre espaço para a atuação dos bancos públicos, mas se trata de uma solução inferior àquela oferecida pelo mercado. 
consolidar a estrutura do seu passivo de forma a adequá-la ao prazo de maturação do investimento, uma vez que somente ao fim deste ele conseguirá obter as receitas necessárias para quitar sua dívida. ${ }^{22} \mathrm{~A}$ empresa busca nas modalidades disponíveis no mercado financeiro a mobilização de fundos de longo prazo para alongar os prazos de suas operações passivas. A este processo a literatura póskeynesiana chamou de funding. É a ausência de mecanismos de consolidação financeira (funding) que constitui obstáculo ao investimento, e não a insuficiência de poupança, como sugere a teoria convencional. ${ }^{23}$

Por meio da ação do multiplicador, os recursos mobilizados para o investimento proporcionarão uma elevação do nível de renda que, dada a propensão marginal a consumir, também elevarão ex-post a taxa de poupança na mesma proporção do aumento inicial do investimento. Se a economia dispuser dos mecanismos apropriados de consolidação financeira, a poupança será alocada em modalidades de longo prazo capazes de alongar o passivo da empresa investidora, completando, assim, o assim chamado circuito financiamento-investimento-poupança-funding.

O mercado de capitais é um dos lócus nos quais o processo de consolidação financeira pode ocorrer: as empresas investidoras negociam junto aos bancos de investimento e outras instituições financeiras atuantes neste mercado os recursos de longo prazo para adquirir os bens de capital necessários à viabilidade de seus projetos (ZONISTEIN, 1989).

Nem todas as economias, contudo, dispõem de mercados de capitais profundos o bastante para completar o circuito. O formato através do qual o funding será provido dependerá das características da estrutura do sistema financeiro. Zysman (1983) propôs uma tipologia que permite classificar as estruturas financeiras existentes. De um modo geral, haveria sistemas com base no mercado de capitais (capital market-based-systems) e sistemas com base no crédito (credit-based systems). No primeiro caso, emissões de ações e debêntures de longo prazo constituem a mais importante fonte de consolidação financeira, enquanto no segundo caso o mercado de capitais é fraco e as firmas dependem do crédito para obter recursos ${ }^{24}$ (STUDART, 1999, p. 163). Não é possível hierarquizar os dois sistemas: as experiências históricas apontam que ambos foram funcionais para o desenvolvimento econômico de seus respectivos países. Em países em que

[...] os canais de consolidação financeira não se desenvolvem de forma significativa, a acumulação requereu uma relação mais próxima entre bancos privados e empresas (do tipo grandes bancos alemães) e/ou uma maior intervenção governamental (como, por exemplo, a criação de bancos de desenvolvimento e políticas

22 Assumindo-se, obviamente, o êxito do empreendimento.

23 Os artigos de Studart (1994, 1999) aprofundam a discussão deste mecanismo.

24 Além, é claro, dos lucros retidos. 
de crédito seletivo nos países de industrialização recente). (STUDART, 1999, p. 163). ${ }^{25}$

Studart (1993) analisou as condições de estabilidade financeira para os dois padrões de estrutura financeira propostos por Zysman. Os sistemas com base em mercado de capitais seriam mais sensíveis a "[...] oscilações e surtos especulativos nos mercados de estoques de ativos" (STUDART, 1993, p. 113), enquanto aqueles baseados no crédito são mais sensíveis às oscilações das taxas de juros de curto prazo, pois em sistemas deste tipo as empresas inversoras são, muitas vezes, obrigadas a rolar continuamente suas dívidas sob taxas flutuantes.

Carvalho et al. (2001) acrescentam que sistemas com base em mercados de capitais dependem essencialmente do tamanho e da profundidade dos mercados de títulos de longo prazo, bem como do tamanho e do perfil dos investidores institucionais, ao passo que os sistemas com base em crédito dependem do perfil de aplicação das famílias e dos investidores institucionais, e do perfil dos próprios bancos.

Um padrão institucional bastante comum em economias que não dispõem de mercados de capitais suficientemente profundos é o uso de bancos públicos de desenvolvimento (BPD) para prover a oferta de recursos de longo prazo e assim completar o circuito financiamento-investimento-poupança-funding. Nessas economias, o setor bancário é preponderantemente constituído por instituições privadas cujas operações passivas não são longas o bastante para sustentar ativos com maturidades muito longas, e por esta razão os BPD assumem papel primordial.

Esse padrão não é considerado na tipologia proposta por Zysman. Embora também se enquadre em um típico credit-based system, as condições de estabilidade de sistemas protagonizados por BPD são distintas.

BPD devem ser configurados de tal forma que suas operações passivas sejam longas e estáveis. Em geral, a estrutura do passivo dos bancos de desenvolvimento é formada por recursos do governo (banco central, recursos fiscais ou para-fiscais), depósitos do público, recursos externos e captações junto ao mercado de capitais. Os formatos não são excludentes, sendo comum que os BPD sejam configurados a partir de um mix das três formas de captação. Evidentemente, um ou dois tipos são preponderantes, de acordo com as condições e necessidades de cada país. O que se observa é que a obtenção de recursos via colocação de títulos nos mercados de capitais é mais comum nos países nos quais estes mercados são organizados e dispõem de um leque maior de instrumentos financeiros. Já nos países em que, ao

25 Alguns dados sugerem que a tipologia proposta por Zysman deve ser, no mínimo, relativizada. Segundo Stiglitz (1993), a média anual de recursos líquidos para financiamento obtidos pelas empresas via fontes internas para o período 1970-79 variou de 66,3\% na França a 91,3\% no Reino Unido; na Alemanha, foi de 80,6\%; no Japão foi de 71,7\%. Nos Estados Unidos, tipicamente considerado um capital-market based system, em média $91,3 \%$ dos recursos foram obtidos via fontes internas, contra somente $17,1 \%$ do mercado acionário e $16,6 \%$ dos bancos. 
contrário, os mercados de capitais têm dimensão insuficiente ou não dispõem da totalidade necessária dos instrumentos, os recursos obtidos por este instrumento não são majoritários entre as operações passivas dos BPD, que assim obtêm seus recursos por meio das outras duas alternativas.

A captação de depósitos do público constitui um formato mais comum (mas não exclusivamente) em instituições financeiras híbridas, como bancos comerciais com carteira de desenvolvimento, sendo pouco usual em BPD. Evidentemente, as operações voltadas para o financiamento do desenvolvimento não podem estar atreladas a depósitos à vista, e sim a depósitos a prazo. Portanto, para que este padrão seja bem-sucedido, é necessário que estes últimos constituam a opção preferencial de captação de depósitos - caso contrário, o banco de desenvolvimento atuará preponderantemente na oferta de finance, em lugar do funding, ou seja, não será capaz de ofertar o financiamento de longo prazo em condições estáveis. Os depósitos a prazo, alternativamente, podem cumprir estes requisitos, desde que possuam características adequadas a este fim, como condições privilegiadas de remuneração para os depósitos com prazos mais longos em comparação com os demais (BNDES, 1992).

A obtenção de recursos externos pode ocorrer por meio de mercados financeiros internacionais ou instituições multilaterais. O primeiro caso requer algum grau de integração da economia que demanda tais recursos com os mercados financeiros internacionais, bem como a adoção de padrões mínimos de governança exigidos pelos operadores dos mercados financeiros internacionais. Entretanto, na fase de contração cíclica da liquidez internacional, as condições de captação de recursos nesta modalidade tendem a se deteriorar, tanto em termos de taxas como de prazos. Já a obtenção de empréstimos por instituições multilaterais, como o Banco Mundial, requer condições mais amplamente atendidas pelos países associados, e normalmente os recursos são contratados para financiar projetos específicos, sem garantia de renovação, o que torna essas fontes algo instável, e muitas vezes o BPD que as utiliza se torna mero repassador e gestor dos recursos. Por fim, por tratar-se de recursos externos, a economia que deles dispuser não poderá perder de vista a necessidade de preservar a saúde intertemporal do seu balanço de pagamentos: a operação implica o aumento do passivo em moeda estrangeira, impondo um risco cambial. Deste modo, o recomendável é que os recursos de origem externa constituam fonte complementar às fontes domésticas. $\mathrm{O}$ uso de recursos externos pode ser indicado, por exemplo, para financiar componentes importados dos projetos de desenvolvimento que compõem o objetivo da operação, ou para financiar projetos que resultarão em aumento futuro das exportações.

Por fim, a obtenção de recursos para o BPD também pode ser feita em moeda doméstica por recursos providos pelo governo. De fato, este constitui a maioria dos casos. Há dois arranjos institucionais através dos quais o governo pode prover 
os seus BPD com recursos em moeda doméstica. $\mathrm{O}$ primeiro é aquele no qual o banco central adquire títulos emitidos pelo banco de desenvolvimento e que, na prática, significa que o financiamento de longo prazo está sendo realizado através de expansão monetária. ${ }^{26}$ Arranjos institucionais nos quais as autoridades monetárias provêm recursos aos seus bancos de desenvolvimento têm com principal característica a facilidade com a qual os recursos são gerados. Em tese, não há limites para que a demanda por financiamento de longo prazo seja acomodada pelo banco central, exceto a preocupação com a suposta aceleração inflacionária que este modelo poderia gerar. O consenso teórico segundo o qual o financiamento do desenvolvimento por meio de expansão monetária é inflacionário provocou paulatinamente a sua substituição por recursos fiscais ou parafiscais, considerados não inflacionários.

Um arranjo institucional alternativo e muito mais comum é aquele no qual o tesouro provê os recursos para o BPD. O repasse de recursos do tesouro pode ser através de medidas como: (i) aumento ou criação de novos impostos ou contribuições específicas; ou (ii) empréstimos voluntários ou compulsórios, a fim de prover recursos adicionais ao banco de desenvolvimento. A viabilidade de tais medidas dependerá da capacidade para elevar a dívida bruta do setor público ${ }^{27}$ ou a carga tributária, e da disposição do governo em encarar os custos políticos decorrentes dessas decisões. O problema é que como a arrecadação de impostos e contribuições é pró-cíclica, durante as recessões a oferta de funding pode ficar comprometida. A gravidade do problema dependerá da sensibilidade do investimento à recessão e, portanto, da sensibilidade da demanda por funding. Não se deve, portanto, excluir a possibilidade de o tesouro aportar novos recursos para viabilizar novos recursos, caso se diagnostique que a recuperação econômica está comprometida em razão da insuficiência de oferta de funding. Se o tesouro for capaz de garantir a oferta de recursos para o BPD, a oferta de funding será adequadamente suprida através deste arranjo institucional. Em sistemas deste tipo, a oferta de funding fica isolada das fontes de instabilidades que afetam os outros dois sistemas da tipologia de Zysman. Isto não quer dizer que são mais estáveis os sistemas baseados em bancos de desenvolvimento cujos recursos são providos pelos tesouros. Eventualmente, por decisões políticas, o tesouro pode destinar menos recursos ao BPD, em nome de alguma outra prioridade, comprometendo a capacidade de oferta de funding nesta economia.

Nesse caso, a existência de fundos fiscais específicos atrelados ao BPD, preferencialmente estabelecidos por força de lei e isolados de decisões políticas dis-

26 Ver, por exemplo, Torres Filho (1983), Okazaki $\&$ Ueda (1995) e Allen (1980), para o caso japonês no imediato pós-II Guerra Mundial, e Cole $\mathcal{E}$ Park (1983) para o caso coreano após a Guerra da Coreia.

27 Ou mesmo da dívida interna líquida, nos casos em que as taxas de juros dos empréstimos do BPD forem inferiores às taxas as quais o Tesouro paga pela dívida emitida. 
cricionárias, garantirá maior estabilidade a este arranjo. Em outras palavras, um arranjo que tenha como base a poupança compulsória tende a garantir um fluxo mais estável de recursos, porque é associado à arrecadação fiscal ou parafiscal, além de contar com o aval do setor público, que detém o poder de criar impostos e contribuições (Cintra, 2009: 63).

\section{Considerações Finais}

A contribuição deste trabalho está na delimitação da importância dos bancos públicos de desenvolvimento a partir de um arcabouço teórico que não assume a primazia dos mercados financeiros. Nesse sentido, pretende-se ter contribuído para preencher uma lacuna existente na teoria econômica, na qual são fartas as contribuições que assumem o BPD como uma solução compatível com a existência de falhas de mercado - e, por esta razão, uma solução tipo second best -, mas são escassas as contribuições que atribuam a este tipo de arranjo institucional a possibilidade de protagonizar o processo de consolidação financeira.

Ao recorrer às categorias pós-keynesianas de incerteza e preferência pela liquidez, é possível oferecer elementos que permitem sustentar uma agenda de fortalecimento dos BPD e que podem ser sintetizados da forma a seguir.

O primeiro resultado relevante é que a abordagem pós-keynesiana para BPD é incompatível com uma hierarquização do sistema financeiro semelhante àquela oferecida pelas abordagens convencional e das falhas de mercado. Nestas duas últimas, os mecanismos de mercado são sempre superiores à intervenção estatal por meio de bancos públicos, cuja ação deve se restringir a atuar nas incompletudes do mercado, sendo a principal delas o financiamento de longo prazo, a qual constituiria a modalidade principal de atuação dos BPD, que ao mesmo tempo restringiria a sua atuação aos limites da oferta de recursos não suprida pelos mecanismos privados. Sob esta abordagem, a agenda propositiva consiste em reformas que, por um lado, enquadrem os BPD a este marco específico, e, por outro, estimulem o desenvolvimento dos mecanismos de mercado para gradativamente substituir os BPD pelos mecanismos privados de mercado.

Já na abordagem pós-keynesiana, esta hierarquização perde o sentido, porque as limitações dos mecanismos de mercado não dependem das falhas ou incompletudes, mas são da própria natureza da firma bancária privada. Sob certas circunstâncias associadas ao próprio ciclo econômico, mas também aos projetos de maior prazo de maturação, ou que envolvem inovação, ou ainda, de retorno incerto por estarem localizados em regiões periféricas, a firma bancária tende a preferir a liquidez ao retorno associado a esses projetos. Com efeito, a ação anticíclica, o financiamento de longo prazo para a formação bruta de capital, para o desenvolvimento regional e para a inovação são funções que devem ser exer- 
cidas pelo banco público mesmo em economias nas quais os mercados financeiros sejam completos e que supostamente não possuam falhas de mercado. $\mathrm{Na}$ abordagem pós-keynesiana, a agenda da liberalização dos mercados financeiros e o desenvolvimento dos mecanismos privados para prover o financiamento de longo prazo perde o status de imposição técnica e deixa de constituir prioridade na agenda de reformas financeiras, dando lugar a outra agenda, mais permeável à ação do setor público por meio do $\mathrm{BPD}$, que pode até mesmo assumir papel não mais complementar ao setor privado, mas de protagonista do processo do financiamento de longo prazo.

Neste caso, o aspecto propositivo se desloca para o desenho mais adequado do BPD, especialmente no que toca à disponibilidade de fontes estáveis de recursos para o adequado cumprimento de suas funções. O desenho mais adequado não permite delimitar a priori o seu tamanho - total de ativos, saldo ou fluxo de operações de crédito, patrimônio líquido etc - não fazendo sentido, nesta abordagem, qualquer menção a agigantamento ou encolhimento do BPD. Seu tamanho, medido sob qualquer desses critérios, deve ser dado em razão da magnitude dos projetos que irá financiar.

Como se espera que as operações ativas do BPD sejam compostas, em sua maioria, por aquelas de prazo mais longo, suas operações passivas devem adequar-se a este perfil. Além disso, suas fontes de recursos não devem ser procíclicas, exatamente para que a ação do BPD não esteja submetida às vicissitudes do ciclo econômico.

O arranjo no qual as operações passivas do BPD são compostas essencialmente por recursos externos deve ser descartado nas economias que se deparam com restrição externa crônica, pois a ocorrência de crises cambiais pode afetar de forma contundente a sua atuação. A maior parte das suas fontes de recursos deve ser obtida em moeda doméstica, reservando aos recursos em moeda estrangeira um caráter meramente complementar.

A possibilidade de o BPD ter nos mercados de capitais a sua principal fonte de captação de recursos restringe-se às economias que já disponham a priori de mercados de capitais profundos o suficiente para sustentar a rolagem de suas fontes.

Finalmente, a captação de recursos por meio de arranjos nos quais o tesouro arrecada impostos e contribuições fiscais e parafiscais específicas pode constituir uma fonte estável de recursos, que ainda podem ser complementados por emissão de dívida pública. Atrelar parte da arrecadação ao BPD é uma forma de assegurar que instabilidades de ordem política não atinjam a atuação do banco de desenvolvimento. Contudo, como essas fontes são pró-cíclicas, devem ser complementadas por endividamento público nos momentos em que forem executadas as políticas contracíclicas que envolvem aumento do gasto com formação bruta de capital. 
O pressuposto para o funcionamento deste padrão passa pela disposição da sociedade em arcar com o aumento da carga tributária e pelas condições de saúde das finanças públicas, já que pode acarretar aumento do endividamento do setor público.

\section{Referências}

AGHION, B. A. Development banking. Journal of Development Economics, v. 58, n. 1, p. 83100, 1999.

ALLEN, G. C. Japan's economic policy. London: The MacMillan Press, 1980.

AMADO, A. A questão regional e o sistema financeiro no Brasil: uma interpretação póskeynesiana. Estudos Econômicos, v. 27, n. 3, p. 417-440, 1997.

. Bancos privados e públicos regionais em uma perspectiva de desenvolvimento regional. In: JAYME JR., F. G.; CROCCO, M. Banco público e desenvolvimento. Rio de Janeiro: Ipea, 2010.

BANCO NACIONAL DE DESENVOLVIMENTO ECONÔMICO E SOCIAL (BNDES). Considerações sobre o financiamento do investimento em países selecionados: Japão, Alemanha, Itália e México. Rio de Janeiro: BNDES, 1992. (Texto para Discussão n. 4).

BIELSCHOWSKY, R. Pensamento Econômico Brasileiro: o ciclo ideológico do desenvolvimentismo: 1930-1964. Rio de Janeiro: Contraponto, 2000.

BOSKEY, S. Problems and practices of development banks. Baltimore: The Johns Hopkins Press, 1959.

BUSATO, M. I. Crescimento econômico e restrição externa: um modelo de simulação. Rio de Janeiro: Beco do Azougue, 2012.

CARNEIRO, R. Desenvolvimento em crise: a economia brasileira no último quarto do século XX. São Paulo: Editora da Unesp, 2002.

CARVALHO, F. C. Sobre a preferência pela liquidez dos bancos. In: PAULA, L. F.; OREIRO, J. L. Sistema financeiro: uma análise do setor bancário brasileiro. Rio de Janeiro: Campus, 2007.

CARVALHO, F. J. C. et al. Economia monetária e financeira: teoria e política. Rio de Janeiro: Elsevier, 2001.

CHO, Y. J.; SHENG, A. Risk management and stable financial. In: CAPRIO, G.; HONOHAN, P.; VITTAS, D. (Ed.) Financial sector policy for developing countries: a reader. Washington: World Bank and Oxford University Press, 2002.

CINTRA, M. A. M. Crédito público e desenvolvimento econômico: a experiência brasileira. In: FERREIRA, F. M. R.; MEIRELLES, B. B. (Org.). Ensaios sobre economia financeira. Rio de Janeiro: BNDES, 2009. 
COLE, D. C.; PARK, Y. C. Financial development in Korea: 1945-1978. Cambridge, MA: Harvard University Press, 1983.

CROCCO, M.; FIGUEIREDO, A. T. L.; SANTOS, F. B. T. Differentiated banking strategies across the territory: an exploratory analysis. Journal of Post Keynesian Economics, v. 133, n. 1, p. 127-150, 2010.

DIAMOND, W. Development Banks. Baltimore: Johns Hopkins University Press, 1957.

FEIJÓ, C. Decisões empresariais em uma economia monetária de produção. In: LIMA, G. T.; SICSÚ, J.; PAULA, L. F. (Org.) Macroeconomia Moderna: Keynes e a Economia Contemporânea. Rio de Janeiro: Campus, 1999.

FERREIRA, C. K. L.; FREITAS, M. C. P.; SCHWARTZ, G. Formato institucional do sistema monetário e financeiro. Um estudo comparado. In: CINTRA, M. A. M.; FREITAS, M. C. P. Transformações institucionais dos sistemas financeiros. um estudo comparado. São Paulo: Fundap/Fapesp, 1998.

FRY, M. In favour of financial liberalization. The Economic Journal, v. 107, n. 442, p. 754-770, 1997.

GURLEY, J. G.; SHAW, E. S. Financial aspects of economic development. The American Economic Review, v. 55, n. 4, 1955

HERMANN, J. Bancos públicos em sistemas financeiros maduros: perspectivas teóricas e desafios para os países em desenvolvimento. Revista de Economia Política, v. 31, n. 3 (123), p. 397-414, 2011.

KEYNES, J. M. Teoria geral do emprego, do juro e da moeda. Rio de Janeiro: Fundo de Cultura, 1964.

LUNA, F.; MOREIRA, S.; GONÇALVES, A. Financiamento à inovação. In: NEGRI, J. A.; KUBOTA, L. C. Políticas de Incentivo à Inovação Tecnológica. Brasília, DF: Ipea, 2008.

MCKINNON, R. I. Money 8 capital in economic development. Washington: The Brookings Institution, 1973.

MINSKY, H. Estabilizando uma economia instável. Osasco: Novo Século, 2009.

NOGUEIRA, M.; CROCCO, M.; SANTOS, F. Sistema financeiro e atuação dos bancos públicos no desenvolvimento regional no Brasil. In: JAYME JR., F. G.; CROCCO, M. Banco público e desenvolvimento. Rio de Janeiro: Ipea, 2010.

OKAZAKI, T.; UEDA, K. The Performance of Development Banks: The case of the Reconstruction Finance Bank. Journal of Japanese and International Economies, v. 9, n. 4, p. 486-504, 1995.

OLIVEIRA, G. O comportamento da estrutura patrimonial de grandes bancos privados diante do recente ciclo de crédito no Brasil - 2002-05. Indicadores Econômicos FEE, v. 34, n. 4, p. 179-196, 2007. 
PAULA, L. F. Riscos na atividade bancária em contexto de estabilidade de preços e alta inflação. Revista Análise Econômica, v. 18, n. 33, p. 93-112, 2000.

. Sistema financeiro, bancos e financiamento da economia: uma abordagem keynesiana. Rio de Janeiro: Elsevier, 2014.

. Teoria da firma bancária. In: LIMA, G. T. et al. Macroeconomia moderna: Keynes e a economia contemporânea. Rio de Janeiro: Campus, 1999.

SERRANO, F. Acumulação e gasto improdutivo na economia do desenvolvimento. In: FIORI, J. L.; MEDEIROS, C. Polarização mundial e crescimento. Petrópolis: Vozes, 2001.

SHAW, E. S. Financial deepening in economic development. New York: Oxford University Press, 1973.

STIGLITZ, J. The role of the state in financial markets. The World Bank Economic Review, v. 7, n. 1, p. 19-52, 1993.

STIGLITZ, J.; WEISS, A. Credit rationing in markets with imperfect information. The American Economic Review, v. 71, n. 3, p. 393-410, 1981.

STUDART, R. O sistema financeiro e o financiamento do crescimento: uma alternativa póskeynesiana à visão convencional. In: LIMA, G. T. et al. Macroeconomia Moderna: Keynes e a economia contemporânea. Rio de Janeiro: Campus, 1999.

. O sistema financeiro e o financiamento do crescimento: uma alternativa pós-keynesiana $\overline{a ̀ ~ v i s a ̃ o ~ c o n v e n c i o n a l . ~ R e v i s t a ~ d e ~ E c o n o m i a ~ P o l i ́ t i c a, ~ v . ~ 13, ~ n . ~ 1, ~} 1993$.

. The efficiency of the financial system and economic development. In: ENCONTRO NACIONAL DE ECONOMIA, 22., 1994, Florianópolis. Anais... Florianópolis: Anpec, 1994.

TITELMAN, D. La banca de desarrollo y el financiamiento productivo. Santiago: Comissão Econômica para a América Latina e Caribe, 2003. (Serie Financiamiento del Desarrollo, n. 137).

TORRES FILHO, E. T. O mito do sucesso: uma análise da economia japonesa no pós-guerra (1945-1978). Rio de Janeiro: UFRJ-IEI, 1983. (Texto para discussão n. 37).

VARIAN, H. Microeconomic analysis. New York: W. W. Norton, 1992.

VITTAS, D.; CHO, Y. J. Credit policies: lessons from East Asia. Washington, D.C.: The World Bank, 1995. (Policy Research Working Paper n. 1458).

YEYATI, E. L.; MICCO, A.; PANIZZA, U. Should the government be in the banking business? The role of state-owned and development banks. Washington: Inter-American Development Bank, 2004. (Working Paper n. 517).

YOSHINO, J. A. Financiamento do Desenvolvimento: as políticas de financiamento de longo prazo, funding e formatação das instituições financeiras de desenvolvimento. Brasília, DF: ABDE, 1994. 
ZONINSEIN. J. O circuito financiamento-investimento-poupança financeira. In: AMADEO, E. Ensaios sobre economia política moderna: teoria e história do pensamento econômico, 1989.

ZYSMAN, J. Governements, markets and growth: financial systems and the politics of industrial change. London: Martin Robertson, 1983.

Recebido em: 25/01/2015.

Aceito em: 19/09/2017. 